ozonized for $1 \mathrm{~h}$ in a fluidized bed reactor (capacity ca. 100 $\mathrm{mL}$ ) with $\mathrm{O}_{2} / \mathrm{O}_{3}$ mixtures ( 6 vol.- $\%$ ozone). About $0.02 \mathrm{~mol}$ of hyperoxide was converted per run. Optimal reaction temperatures are $5^{\circ} \mathrm{C}$ and $20^{\circ} \mathrm{C}$ for $\mathrm{KO}_{3}$ and $\mathrm{RbO}_{3}$, respectively. The reaction can be monitored by the change in color of the reaction mixture from yellow to intense red.

For the growth of single crystals the ozonides were extracted at $-40^{\circ} \mathrm{C}$ with liquid ammonia, while unreacted hyperoxide remained undissolved. The solvent was then removed under argon with cooling; the alkali-metal ozonides precipitated as transparent deep-red crystals. The single crystals for the $\mathrm{X}$-ray structure analysis were prepared under an inert gas at $10^{\circ} \mathrm{C}$.

The X-ray structure analyses ${ }^{[3]}$ confirm the predicted composition of the alkali-metal ozonides. Isolated angular $\mathrm{O}_{3}^{-}$ions are present whose dimensions in $\mathrm{RbO}_{3}(\mathrm{O}-\mathrm{O}(\mathrm{av}-$ eraged) $134.1(15) \mathrm{pm}$, bond angle $114.6(13)^{\circ}$ ) and $\mathrm{KO}_{3}$ $\left(135.7(5) \mathrm{pm}\right.$, bond angle $\left.113.4(8)^{\circ}\right)$ agree within the standard deviations ${ }^{[3]}$. Thus, packing effects seem to have no significant impact on the geometry of the anion. With respect to the bond lengths and angles previously determined on the basis of inadequate data ${ }^{(1 \mathrm{c})}\left(\mathrm{RbO}_{3}: 142(9) \mathrm{pm}, 101(5)^{\circ}\right.$, $\mathrm{KO}_{3}: 119 \mathrm{pm}, 100^{\circ}$ ), there are considerable discrepancies.

\section{Crystal Structures of Potassium Ozonide and Rubidium Ozonide**}

\section{By Wolfgang Schnick and Martin Jansen*}

In the case of main group elements, bond systems with uneven numbers of electrons are an exception to the rule; on the other hand, a host of such systems appears to exist in the case of triatomic units with 19 valence electrons. This may be a coincidence. But there are also indications of such systems being especially stable: for example, the markedly low tendency for chlorine dioxide to dimerize. As further supporting evidence of this concept, one could mention the tendency of $\mathrm{N}_{2} \mathrm{~F}_{4}$ to dissociate into $\mathrm{NF}_{2}$ radicals, or the exceptionally long $\mathrm{S}-\mathrm{S}$ bond in the dithionite ion ( $239 \mathrm{pm}$, bond order noticeably less than one), indicating a tendency for decomposition into two $\mathrm{SO}_{-}^{-}$moieties. The group of 19-electron systems also includes the ozonide ion $\mathrm{O}_{3}$. However, despite intensive studies over the past twenty years and more ${ }^{[1]}$, the existence of this anion has still not been unequivocally settled. In particular, there has been lack of reliable data on its geometry: thus, the data on experimentally determined $\mathrm{O}-\mathrm{O}$ bond lengths vary between 119 and $142 \mathrm{pm}$, with the $\mathrm{O}-\mathrm{O}-\mathrm{O}$ angle being

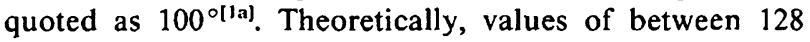
and $135 \mathrm{pm}$ are predicted for the bond lengths and between 108 and $120^{\circ}$ for the bond angle. We have now determined the dimensions of the ozonide ion by $\mathrm{X}$-ray structure analyses on single crystals of $\mathrm{KO}_{3}$ and $\mathrm{RbO}_{3}$.

Of the possible strategies available for the preparation of alkali-metal ozonides ${ }^{[1 \mathrm{cl}]}$, it was found from detailed preliminary investigations that the reaction of solid potassium or rubidium hyperoxide with $\mathrm{O}_{2} / \mathrm{O}_{3}$ mixtures was the most suitable. The hyperoxides of potassium and rubidium, obtained by oxidation of the alkali metals with $\mathrm{O}_{2}{ }^{(2)}$, were

[*] Prof. Dr. M. Jansen, Dipl.-Chem. W. Schnick Institut für Anorganische Chemie der Universität Callinstr. 9, D-3000 Hannover I (FRG)

$\left.{ }^{* *}\right]$ This work was supported by the Deutsche Forschungsgemeinschaft and the Fonds der Chemischen Industrie.

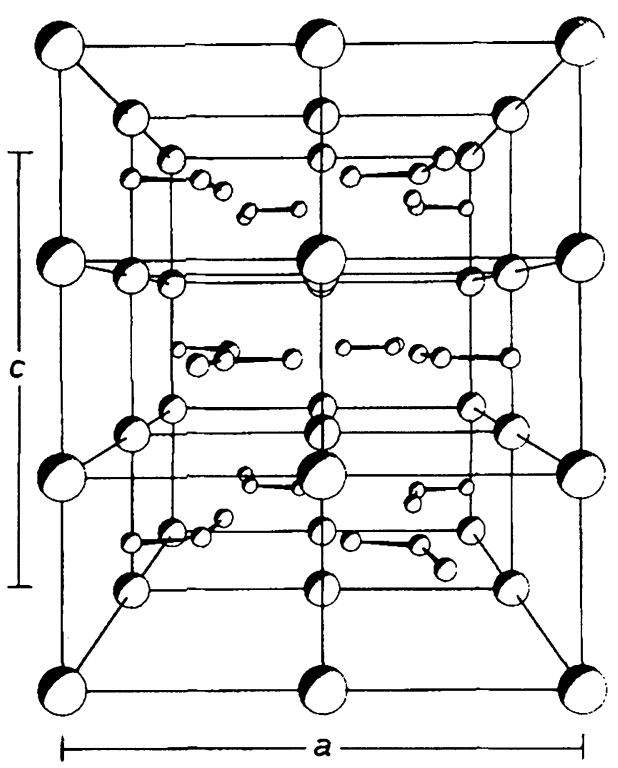

Fig. 1. Perspective diagram of the crystal structure of $\mathrm{KO}_{3}$, viewed along [100]; large circles denote potassium, small circles oxygen.

The $\mathrm{O}-\mathrm{O}$ bonds are longer than in ozone $(127.8 \mathrm{pm})^{[4]}$. Since the additional electron occupies an antibonding molecular orbital, this tendency is consistent with expectation. The bond angle is reduced slightly from $116.8^{\circ}$ to $114.0^{\circ}$. The distance between the two terminal oxygen atoms increases significantly from 218 to $226 \mathrm{pm}$.

With considerable simplification the packing of $\mathrm{K}^{+}$or $\mathrm{Rb}^{+}$and $\mathrm{O}_{3}^{-}$to a three-dimensional crystal array can be rationalized as the $\mathrm{CsCl}$-type structure (Fig. 1). The shortest contacts between oxygen and alkali-metal ions are, in the case of $\mathrm{KO}_{3}$ exclusively and in the case of $\mathrm{RbO}_{3}$ predominantly, those at the terminal O-atoms of the anion. This structural feature enables qualitative conclusions to be drawn about the polarity of the ozonide ion. Common to both ozonides is a marked deviation (86 pm $\left(\mathrm{KO}_{3}\right), 58$ $\mathrm{pm}\left(\mathrm{RbO}_{3}\right)$ ) of the anion from the center of the polyhedron that is formed by the eight alkali-metal ions. There is still 
no satisfactory explanation for the complete order of the ozonide anions at room temperature, which is in contrast with the comparable $\mathrm{RbNO}_{2}{ }^{[5]}$. Intermolecular interactions between the ozonide ions (dimerization) can be ruled out on the grounds of the large intermolecular distances ${ }^{[3]}$. Also still inexplicable are the marked differences in the stability of the compounds with 19-electron systems $\left(\mathrm{NF}_{2}\right.$, $\mathrm{SO}_{2}^{-}, \mathrm{O}_{3}, \mathrm{~S}_{3}, \mathrm{ClO}_{2}$ ) towards dimerization. Whichever of the conceivable criteria is analyzed for an explanation (repulsion of non-bonding electron pairs, differences in electronegativity ${ }^{[6]}$, charge of the monomer, state of aggregation) there are inconsistencies.

Received: September 5, 1984; revised: October 22, 1984 [Z 983 IE] German version: Angew. Chem. 97 (1985) 48

[1] a) L. V. Azároff, I. Corvin, Proc. Nat. Acad. Sci. USA 49 (1963) 1; V. A Sarin, V. Y. Dudarev, M. S. Dobrolyubova, Kristallografiya 19 (1974) 74; b) P. Smith, J. Phys. Chem. 60 (1956) 1471; L. Pauling: The Nature of the Chemical Bond. Cornell Univ. Press, New York 1980, p. 354; S. Schlick, J. Chem. Phys. 56 (1972) 654; c) A. D. McLachlan, M. C. R. Symons, M. G. Townsend, J. Chem. Soc. 1959. 952; I. I. Vol'nov, E. I. Sokevnin, V. V. Matveev, Izv. Akad. Nauk SSSR 6 (1962) 1127; I. I. Vol'nov, M. S. Dobrolyubova, A. B. Tsentsiper, Izv. Akad. Nauk SSSR Ser. Khim. 9 (1966) 1611.

[2] Prepared analogously to the method described by A. Helms, W. Klemm, Z. Anorg. Allg. Chem. 242 (1939) 33; K. Wahl, Dissertation, Universität Münster 1954.

[3] $\mathrm{KO}_{3}: \quad 14 / \mathrm{mcm}, \quad a=864.80(12), \quad c=716.40(14) \quad \mathrm{pm} \quad\left(-25^{\circ} \mathrm{C}\right)$ $V=535.78 \times 10^{6} \mathrm{pm}^{3}, Z=8$. Siemens AED2 diffractometer, Mo $\mathrm{K}_{\mathrm{K}}$ radiation, graphite monochromator, scan width $2.0^{\circ}, \omega$-scan, 2084 measured reflections with $6.7^{\circ}<2 \theta<65^{\circ}, 147$ symmetry independent reflections with $F>3 \sigma(F)$, anisotropic refinement, $R=0.063$ for 15 free parameters, $R_{w}=0.046, w=4.15 /\left(\sigma^{2}(F)\right)$ selected bond lengths $[\mathrm{pm}]$ and angles $\left[{ }^{\circ}\right]$ (standard deviations in brackets): $\mathrm{O} 1-\mathrm{O} 2$ 135.7(5) $(2 \times), \mathrm{O}^{2}-\mathrm{O} 2$ 226.9(11), O1-O2' 300.5(11) intermolecular, K-O2 285.3(6) $(8 \times)$ $\mathrm{O} 2-\mathrm{O} 1-\mathrm{O} 2^{\prime} \quad 113.4(8) .-\mathrm{RbO}_{3}: \quad \mathrm{P} 2_{1} / \mathrm{c}, \quad a=644.10(22), \quad b=603.00(35)$ $c=874.60(36) \mathrm{pm}\left(-25^{\circ} \mathrm{C}\right), \beta=122.25(2)^{\circ}, V=287.28 \times 10^{\circ} \mathrm{pm}^{3}, Z=4$. Siemens AED2 diffractometer, Mo $_{K_{\alpha}}$ radiation, graphite monochromator, scan width $2.8^{\circ}, \omega$-scan, 1953 measured reflections with $7.5^{\circ}<2 \theta<50^{\circ}, 373$ symmetry independent reflections with $F>3 \sigma(F)$, anisotropic refinement, $R=0.059$ for 37 free parameters, $R_{\mathrm{w}}=0.047$ $w=3.48 /\left(\sigma^{2}(F)\right)$. Selected bond lengths $[\mathrm{pm}]$ and angles $\left[{ }^{\circ}\right]$ (standard de viation in brackets): 01-O2 134.7(15), O1-O3 133.4(17), O2-O2 225.6(16), O1-O3' 299.2(11) intermolecular, O2-O1-O3 114.6(13) $\mathrm{Rb}-\mathrm{O} 2292.2(10), \mathrm{Rb}-\mathrm{O} 3$ 296.7(11), $\mathrm{Rb}-\mathrm{O3}^{\prime}$ 300.3(12), $\mathrm{Rb}-\mathrm{O}^{\prime \prime}$ 300.9(12): Rb-O1 305.8(11), Rb-O2' 306.4(17), Rb-O3"' 307.0(11), $\mathrm{Rb}-02^{\prime \prime} 308.5(12)$. Further details of the crystal structure investigations are available on request from the Fachinformationszentrum Energie Physik Mathematik, D-7514 Eggenstein-Leopoldshafen 2, on quoting the depository number CSD 51112 , the names of the authors, and the journal citation.

[4] R. W. Hughes, J. Chem. Phys. 24 (1956) 131.

[5] P. W. Richter, C. W. F. T. Pistorius, J. Solid State Chem. S (1972) 276

[6] M. Green, J. Chem. Soc. 1962, 2819. 